\title{
Persistent infection with virulent but not avirulent Mycobacterium tuberculosis in the lungs of mice causes progressive pathology
}

\author{
PAMELA L. DUNN and R. J. NORTH \\ Trudeau Institute Inc., PO Box 59, Saranac Lake, NY 12983, USA
}

\begin{abstract}
A strain of Mycobacterium tuberculosis (H37Rv) considered virulent for mice and a strain (R1Rv) considered relatively avirulent were compared for their ability to survive host immunity in the lungs and to induce lung pathology. Although both strains of $M$. tuberculosis were capable of causing a slowly progressive infection in the lungs of immunocompetent mice, only the H37Rv strain was capable of inducing progressive destructive pathology and of causing loss of lung function over a 300-day period. Therefore, the ability to survive host immunity in the lungs and the ability to cause lung pathology are separate manifestations of mycobacterial virulence.
\end{abstract}

\section{Introduction}

Tuberculosis in man is predominantly a disease of the lungs [1]. Moreover, strains of Mycobacterium tuberculosis isolated from human patients with active disease are capable of causing lung disease in various experimental animals [2-4]. It was shown some time ago for mice, $[5,6]$ for example, that intravenous (i.v.) inoculation of $M$. tuberculosis causes progressive disease in the lungs, rather than in other organs. A more recent study revealed [7] that progressive lung disease occurs in mice, in spite of an acquired mechanism of cellular immunity capable of resolving infection in the liver, spleen and kidneys. On the other hand, infection with attenuated strains of mycobacteria are resolved in the lungs, as well as other organs [8]. Therefore, the ability to survive and cause persistent infection in the lungs in the face of systemic immunity is a key manifestation of mycobacterial virulence.

The purpose of this study was to examine whether the ability to cause progressive lung pathology and death of immunocompetent mice is a manifestation of mycobacterial virulence which is distinct from the ability to persist in the lungs.

\section{Materials and methods}

Mice

Immunocompetent female B6D2F $1(\mathrm{C} 57 \mathrm{Bl} / 6 \times \mathrm{DBA} / 2)$ mice were obtained from the Trudeau Institute Animal Breeding Facility (Saranac Lake, NY, USA) and used

Received 31 Aug. 1995; revised version accepted 20 Dec. 1995. Corresponding author: Dr P. L. Dunn. in experiments at 7-9 weeks of age. They were free of common viral pathogens according to routine serological screening performed by the Research Diagnostic Laboratory, College of Veterinary Medicine, University of Missouri. All experiments with animals were carried out in accordance with the regulations outlined in the NIH Guide to the Care and Use of Laboratory Animals.

\section{Bacteria}

Two strains of $M$. tuberculosis, strain H37Rv (TMC \#102) and strain R1Rv (TMC \#205) were obtained from the Trudeau Mycobacterial Culture (TMC) Collection. They were grown and frozen as working stock cultures as previously described [7]. Bacteria were prepared for inoculation by thawing a stock vial, diluting it 10-fold in phosphate-buffered saline (PBS) containing Tween $80 \quad 0.01 \%$, and subjecting the suspension to ultrasonication for $5 \mathrm{~s}$ to break up clumps. The resulting suspension was diluted to the desired concentration in PBS containing Tween 80 $0.01 \%$. Mice were inoculated with $0.2 \mathrm{ml}$ of the final suspension via a lateral tail vein. Bacteria were counted in the organs of infected mice by plating serial 10 -fold dilutions of whole organ homogenates on enriched agar (Middlebrook 7H11; Difco Laboratories), incubating the plates for 2-3 weeks, and counting the number of cfu with $4 \times$ magnification dissecting microscope. All experiments were based on the use of five mice/timepoint.

\section{Histology}

Lungs were fixed in neutral-buffered formalin $10 \%$, washed in running tap water, dehydrated in ethanol and 
embedded in paraffin by standard procedures. Paraffin sections were cut at $5 \mu \mathrm{m}$ with a rotary microtome (AO 820 microtome; American Optical, Buffalo, NY, USA). After dewaxing, the sections were stained for acid-fast bacilli with a modified basic fuchsin stain [9] containing LOC High Suds (Amway Corporation, Ada, MI, USA) $0.6 \% \mathrm{v} / \mathrm{v}$. Sections were then briefly destained with acid-alcohol, and counterstained with either methylene blue or with a water-based MacNeal's tetrachrome stain. Photomicrography was performed with a Nikon Microphot-Fx-microscope. Histological examination was performed on the organs of three mice/time-point.

\section{Results}

\section{Persistent lung infection}

Fig. 1 shows the fate over a 300-day period of the virulent H37Rv strain of $M$. tuberculosis and the avirulent R1Rv strain in the lungs and livers of mice inoculated i.v. with $10^{5}$ bacilli of either strain. In each case, $>90 \%$ of the inoculum was taken up by the liver, with $<1 \%\left(10^{2.5}\right)$ implanting in the lungs. After day 1 , infection with either strain progressed in the liver for $c$. 10 days, after which it underwent resolution to reach a low level that remained stable for a period of 250 days or more. Therefore, there was little or no significant

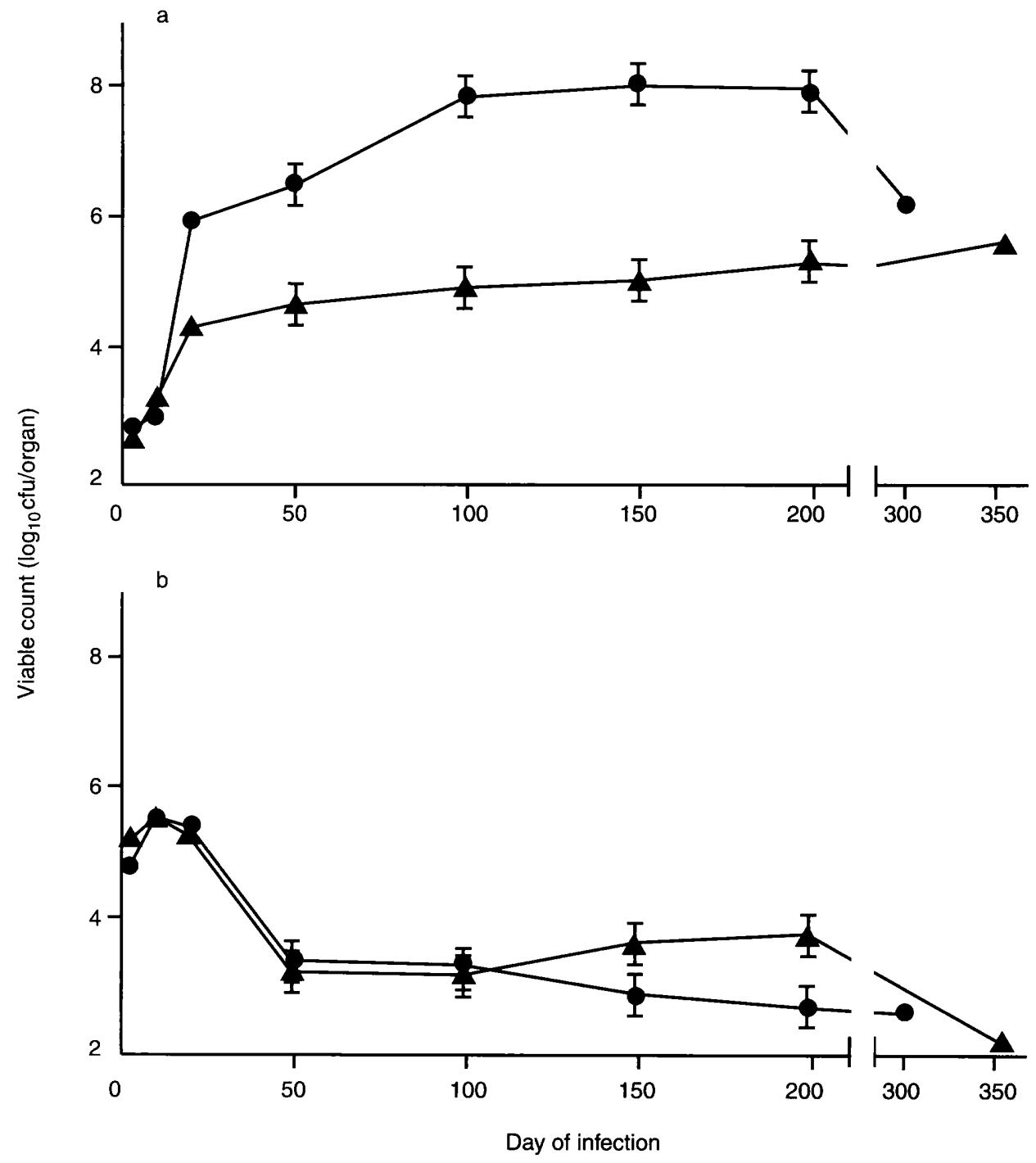

Fig. 1. Growth curves of $M$. tuberculosis R1Rv ( $\Delta$ ) and M. tuberculosis H37Rv (O) in (a) lungs and (b) livers of mice inoculated with $10^{5} \mathrm{cfu}$ of either strain i.v. A 20 -day period of progressive bacillary growth in the lungs was followed by a prolonged period of greatly reduced growth in the case of both organisms, although the level of infection reached at day 20 by strain R1Rv was much lower than by strain H37Rv. In the liver a 10-day period of bacillary growth was followed by resolution of infection to a low level that remained stable for a long period of time. Mice infected with strain $\mathrm{H} 37 \mathrm{Rv}$ began dying at day 250 of infection. After this time the number of strain $\mathrm{H} 37 \mathrm{Rv}$ in the lungs began to decrease, and the level of infection was gradually reduced 100 -fold over the remaining time. Results are means and SD for five mice/time-point. 
difference in the ability of these strains to resist host immunity in the liver. However, in the lungs infection progressed for $c .20$ days, but at a much faster rate in the case of strain H37Rv. This resulted in the lungs of mice infected with this strain having 100 -fold more bacilli on day 20 than those infected with strain R1Rv. After day 20, however, the rate of bacillary growth for each strain was greatly reduced, presumably under the influence of acquired immunity. In the case of strain R1Rv this resulted in a very slowly progressive infection that continued without interruption for $>300$ days. In the case of mice infected with strain H37Rv, lung infection also progressed slowly, but at the higher level, until day 200, after which the bacillary number declined to approach that of strain R1Rv. Mice infected with strain $\mathrm{H} 37 \mathrm{Rv}$ showed signs of respiratory distress and began to die from $c$. day 250 onwards, whereas those infected with strain R1Rv showed no signs of illness during the 350 days of the experiment.

\section{Lung pathology}

The foregoing results show that whilst both a strain of $M$. tuberculosis of high virulence and one of low virulence were capable of causing an infection in the lung which persisted over a long period, only mice infected with the strain of high virulence showed signs of respiratory distress and succumbed to infection. This indicated that the virulent strain is capable of causing more lung pathology than the less virulent strain. To investigate this possibility, the lungs of mice infected for 300 days with either strain were subjected to histological examination.

Strain H37Rv was significantly more capable of inducing lung pathology than strain R1Rv. Low power microscopy (Fig. 2a) showed that in mice infected with strain $\mathrm{H} 37 \mathrm{Rv}$ for 300 days, most of the lung parenchyma was consolidated and had the appearance of end-stage lung disease with a typical honeycomb structure. When viewed at the same magnification, the lungs of mice infected for 300 days with strain R1Rv (Fig. 3a) were almost completely free of pathology, except for some randomly scattered small lesions measuring 100-200 $\mu \mathrm{m}$ across. Presumably, many of these lesions represented sites at which strain R1Rv had originally implanted in the lung.

At high power it was clear that in the lungs of strain H37Rv-infected mice (Fig. 2b) most of the air spaces were occupied by inflammatory cells. This was associated with an expansion and increased cellularity of the interstitium. An electron microscopy study (unpublished observations) showed that the interstitium contained abundant type I collagen and fibroblasts. The honeycomb appearance of consolidated lung viewed at lower power was seen to be the result of the interruption of densely cellular tissue by numerous expanded air sacs, some of which had coalesced into larger structures. Some of the air sacs contained cellular debris while others contained aggregates of intact and degenerating macrophages, many of which contained acid-fast bacilli (Fig. 2b). Most of the air sacs were lined by epithelial-like cells (Fig. 2c), and it was apparent that expansions of the sacs had obliterated individual alveolar outpocketings (Fig. 2d).

The small lung lesions induced by strain R1Rv (Fig. $3 \mathrm{~b}, \mathrm{c})$, on the other hand, consisted of compact accumulations of epithelioid macrophages and other mononuclear cells, as well as occasional neutrophils. Some of the macrophages contained small numbers of acid-fast bacilli, and the lesions as a whole gave the appearance of being relatively stable in composition. Occasionally they were seen in close proximity to extensive aggregates of lymphocytes representing expanded intrapulmonary lymphoid tissue.

\section{Discussion}

M. tuberculosis is an obligate pathogen that has evolved to enter its human host via the respiratory tract and to colonise the lung rather than other organs in the face of systemic immunity. It is apparent that it has also evolved to induce pathology of a type that will ensure its exit from lungs via the respiratory tract in micro-droplets for dispersal by air. The pathology induced in the lungs of immunocompetent humans by M. tuberculosis results in fibrotic encasement of sites of infected tissue followed by caseation of the infected tissue within [10]. This is followed in turn by coalescence of caseous lesions into larger ones that eventually form cavities. This can be associated with denudation of the walls of adjacent bronchioles and with the emptying of the contents of cavities into the bronchioles for expulsion via the respiratory tract.

The results presented here confirm earlier findings [6], showing that tuberculosis in immunocompetent mice is similar to tuberculosis in man in being a disease primarily of the lungs. Inoculating mice with the virulent $\mathrm{H} 37 \mathrm{Rv}$ strain of $M$. tuberculosis i.v. was shown here to result, after an initial period of rapid growth, in a much reduced rate of growth that gave rise to a persistent or slowly progressive infection in the lungs over an extended period of time, even though the level of infection in the liver was reduced $>95 \%$ before day 50 and then stabilised. According to the results of an earlier study from this laboratory [7] the reduced rate of infection in the lung and resolution of infection in the liver is the result of the acquisition of immunity mediated by $\mathrm{CD} 4^{+} \mathrm{T}$ cells, as evidenced by the continuous rapid growth of the pathogen and the early death of mice depleted of this T-cell subset. Early death of $\mathrm{CD}^{+} \mathrm{T}$ cell-depleted mice infected with $M$. tuberculosis has been demonstrated by other workers [11]. Presumably, the $\mathrm{CD}^{+}$ $\mathrm{T}$ cells involved in this type of immunity are predominantly $\mathrm{T}_{H 1}$ cells, given the importance of 

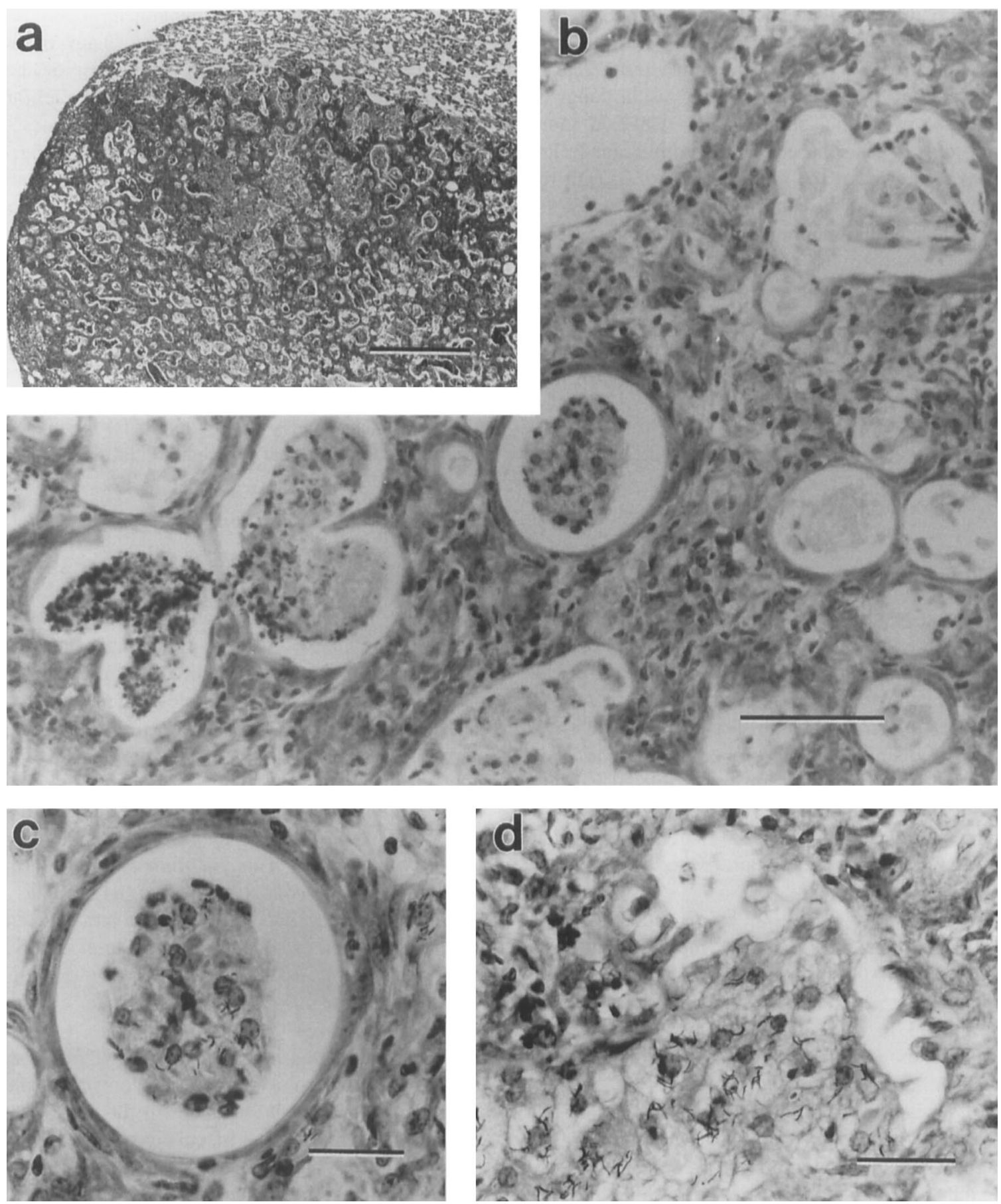

Fig. 2. Persistent lung infection with M. tuberculosis H37Rv resulted over a 300-day period in extensive fibrosis that replaced most of the lung parenchyma. a, At low power the fibrosis was interrupted by many cysts to give the lung a honeycomb appearance. Crystal violet-stain; magnification, $\times 35$; bar $=450 \mu \mathrm{m}$. b. At higher power, the cysts were seen to contain aggregates of disintegrating cells or cell-derived amorphous material. Methylene blue stain; magnification, $\times 353$; bar $=62 \mu \mathrm{m}$. c, Some of the cysts were lined by epithelial-like cells and contained aggregates of epitheloid macrophages containing acid-fast bacilli. d, Other areas contained regions in which less well formed cysts were present. MacNeal's tetrachrome stain; magnification, $\times 600(\mathbf{c}) ;$ bar $=25 \mu \mathrm{m}$, and $\times 520(\mathbf{d})$; bar $=30 \mu \mathrm{m}$.

IFN $_{Y}$ in defence against this pathogen $[12,13]$. This would be in keeping with the interpretations regarding the cellular basis of anti-tuberculosis immunity in recent reviews of this subject $[14,15]$.

The present study also showed that the persistent presence of virulent $M$. tuberculosis in the lungs induced expansive pathology at each site of infection which eventually resulted in consolidation of most of the lung parenchyma and loss of respiratory function. At 250 days of infection and later, this pathology was similar in appearance to the honeycomb end-stage 

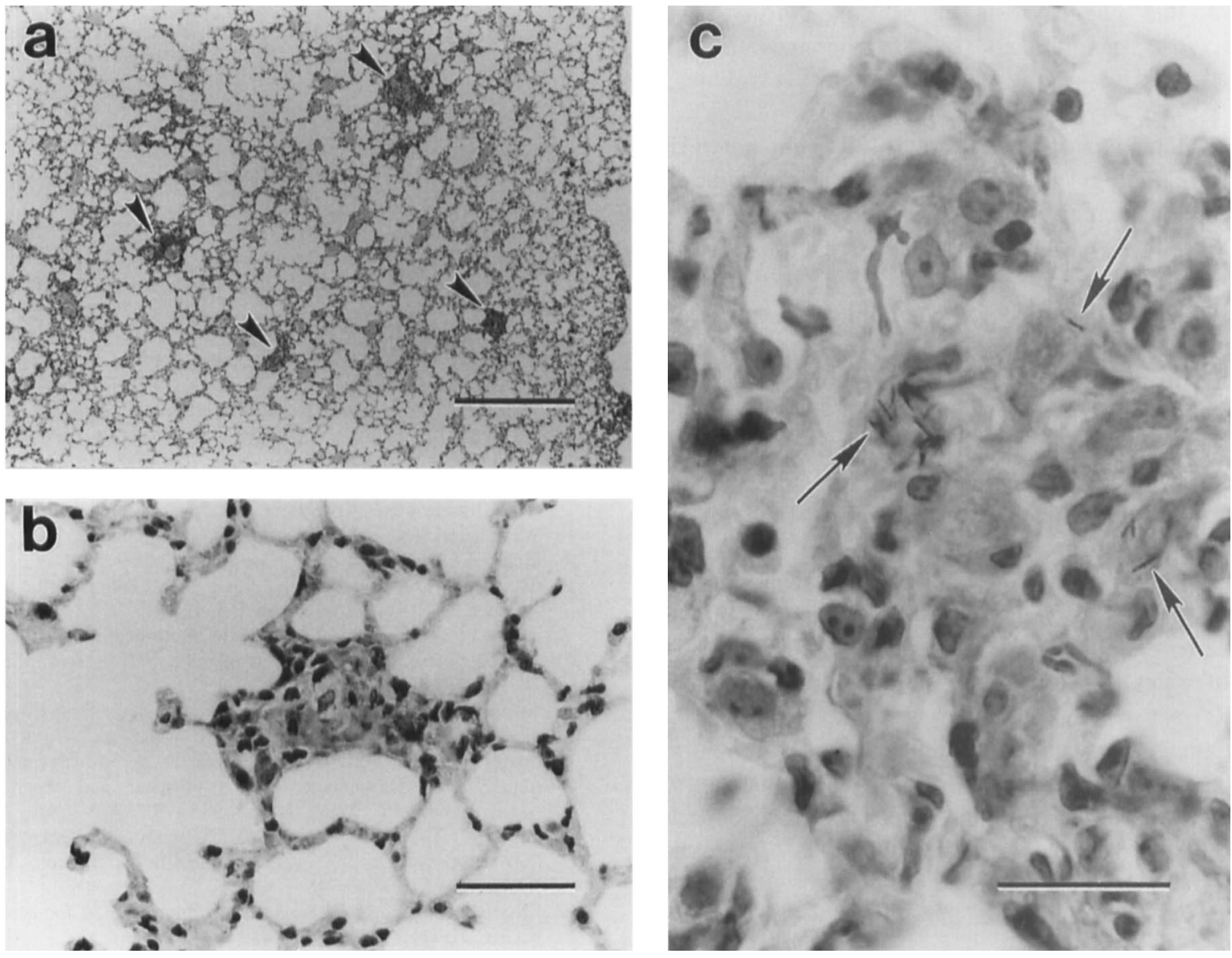

Fig. 3. Persistent lung infection with $M$. tuberculosis R1Rv induced little pathology in this organ over a 300-day period. a, At low power the lung can be seen to contain small randomly distributed, discrete lesions (arrows). Crystal-violetstain; magnification, $\times 35$; bar $=450 \mu \mathrm{m}$. b, At higher power the lesions were seen to represent small compact collections of macrophages and other mononuclear cells. MacNeal's tetrachrome stain; magnification, $\times 360$; bar $=40 \mu \mathrm{m}$. c, At higher power still some of the macrophages (arrows) contained acid-fast bacilli. Magnification, $\times 1075$; bar $=20 \mu \mathrm{m}$.

lung described for human patients with various types of chronic progressive lung disease [16], although not necessarily with tuberculosis.

A key additional finding generated by this study is that the ability of $M$. tuberculosis to persist in the lungs of immunocompetent mice over a long period of time need not be associated with an ability to induce tissue-destructive lung pathology. Thus, the less virulent R1Rv strain of $M$. tuberculosis, although just as capable as the more virulent H37Rv strain at causing persistent infection in the lungs of immunocompetent mice, was very limited in its ability to induce pathology over a 350-day period of infection. In fact, strain R1Rv was capable only of causing small accumulations of macrophages and lymphoid cells at each site of infection. Virulence, therefore, is based on factors in addition to those that enable $M$. tuberculosis to survive host immunity in the lungs. It should be noted that strain $\mathrm{R} 1 \mathrm{Rv}$ differs from attenuated strains, such as Bacillus Calmette Guerin (BCG) and the H37Ra strain of M. tuberculosis, in that infection with these strains undergoes resolution in the lungs as well as in other organs [7].

There is published evidence [17] that the state of stable lung infection that occurs after the acquisition of specific immunity in mice infected with the H37Rv strain of $M$. tuberculosis is associated with conversion of the organism to a non-replicating state that is associated with what is believed to be a state approximating metabolic 'dormancy' [18]. Presumably, the same would apply to stable infection with the avirulent RlRv strain of $M$. tuberculosis. However, given the ability of strain $\mathrm{H} 37 \mathrm{Rv}$, but not $\mathrm{R} 1 \mathrm{Rv}$, to induce progressive pathology over a 300-day period, it could be argued that the former is metabolically more active during this period than the latter. Moreover, because both strains of $M$. tuberculosis reside in epithelioid macrophages throughout the course of infection, it seems reasonable to suspect that the pathology caused by the H37Rv strain results from its enhanced ability to induce these cells to synthesise and secrete cytokines. It is known [19-21], in this 
regard, that phagocytosis of $M$. tuberculosis or $M$. tuberculosis components by macrophages in vitro caused them to secrete pro-inflammatory cytokines.

This explanation of why strain H37Rv, but not R1Rv, causes pathology is in keeping with the additional evidence presented here showing that strain H37Rv has a much faster doubling time than strain $R 1 R v$ in the lungs of mice during the first 20 days of infection ( $44.5 \mathrm{~h}$ versus $84.5 \mathrm{~h}$ ) before immunity is expressed. It has been a general finding $[22,23]$ that virulent strains of mycobacteria have shorter doubling times than attenuated ones, and it is generally considered that a shorter doubling time is a reflection of a higher rate of metabolic activity [24]. Furthermore, it is obvious from this study that a faster doubling time enabled strain H37Rv to grow $2 \log _{10}$ more than strain R1Rv in the lungs during the first 20 days of infection before the expression of host immunity and the consequent stabilisation of infection. This was seen microscopically as a much larger number of strain H37Rv per lesion and a larger number per infected macrophage in sections of lung stained for acid-fast bacilli. It seems reasonable to suggest that macrophages with larger bacillary loads would be expected to synthesise and secrete larger quantities of cytokines and other products than macrophages with smaller bacillary loads. Therefore, the ability of strain H37Rv to multiply almost twice as fast as strain R1Rv and to populate sites of infection with 100 times more bacilli before host immunity is expressed could explain the superior ability of strain $\mathrm{H} 37 \mathrm{Rv}$ to induce pathology. However, it should be mentioned that strain H37Rv was able to continue to cause progressive pathology after day 200 of infection when its number in the lungs was in decline and approaching the number of strain R1Rv. The consequence on lung pathology of inoculating mice with a larger number of strain R1Rv to raise the level of infection reached by this organism to that reached by a lower number of strain $\mathrm{H} 37 \mathrm{Rv}$ is currently being investigated. However, preliminary results indicate that although increasing the inoculum size of strain R1Rv serves to increase the level of infection in the lungs it does not result in progressive pathology. Presumably this is because it serves to increase the number of infectious lesions per lung rather than the number of bacilli per lesion.

In conclusion, the results of this study show that $M$. tuberculosis virulence not only depends on the ability of the organism to persist in the lung in the face of acquired host immunity, but also on the ability to induce destructive pathology in this organ over a long period of time. Both these aspects of virulence need to be considered in attempts to identify virulence genes by recombinant DNA technology.

We thank Joyce Reome, Lynn Ryan and Linda Schaefer for expert technical assistance and Mary Durett for typing the manuscript. This work was supported by grants AI27156, AI37844 and HL51960 from the National Institutes of Health, and a general support grant from the G. Harold and Leila Y. Mathers Charitable Foundation.

\section{References}

1. Farer LS, Lowell AM, Meador MP. Extrapulmonary tuberculosis in the United States. Am J Epidemiol 1979; 109: 205217.

2. Orme IM, Collins FM. Mouse model of tuberculosis. In: Bloom BR (ed) Tuberculosis: pathogenesis, protection, and control. Washington, DC, ASM Press. 1994: 113-134.

3. McMurray DN. Guinea pig model of tuberculosis. In: Bloom BR (ed) Tuberculosis: pathogenesis, protection, and control. Washington, DC, ASM Press. 1994: 135-147.

4. Dannenberg AM. Rabbit model of tuberculosis. In: Bloom BR (ed) Tuberculosis: pathogenesis, protection, and control. Washington, DC, ASM Press. 1994: 149-156.

5. Pierce C, Dubos RJ, Middlebrook G. Infection of mice with mammalian tubercle bacilli grown in tween-albumin liquid medium. J Exp Med 1947; 86:159-174.

6. Pierce C, Dubos RJ, Schaefer WB. Multiplication and survival of tubercle bacilli in the organs of mice. J Exp Med 1953; 97 : 189-205.

7. North RJ, Izzo AA. Mycobacterial virulence. Virulent strains of Mycobacterium tuberculosis have faster in vivo doubling times and are better equipped to resist growth-inhibiting functions of macrophages in the presence and absence of specific immunity. J Exp Med 1993; 177: 1723-1733.

8. Guerin C. The history of BCG. Early history. In: Rosenthal SR (ed) BCG vaccination against tuberculosis. Boston, Littel, Brown and Co. 1957; 48.

9. Ellis RC, Zabrowarny LA. Safer staining method for acid fast bacilli. J Clin Pathol 1993; 46: 559-560.

10. Patel AM, Abrahams EW. Pulmonary tuberculosis. In: Ratledge C, Stanford M, Grange JM (eds) Biology of the mycobacterium, vol. 3. Clinical aspects of mycobacterial disease. London, Academic Press. 1989: 179.

11. Leveton CS, Barnass S, Champion B et al. T cell-mediated protection of mice against virulent Mycobacterium tuberculosis. Infect Immun 1989; 57: 390-395.

12. Cooper AM, Dalton DK, Stewart TA, Griffin JP, Russell DG, Orme IM. Disseminated tuberculosis in interferon $y$ genedisrupted mice. J Exp Med 1993; 178: 2243-2247.

13. Flynn JL, Chan J, Triebold KJ, Dalton DK, Stewart TA, Bloom BR. An essential role for interferon $y$ in resistance to Mycobacterium tuberculosis infection. J Exp Med 1993; 178: 2249-2254.

14. Chan J, Kaufmann SHE. Immune mechanisms of protection. In: Bloom BR (ed) Tuberculosis: pathogenesis, protection, and control. Washington, DC, ASM Press. 1994: 389-415.

15. Barnes PF, Modlin RL, Ellner JJ. T-cell responses and cytokines. In: Bloom BR (ed) Tuberculosis: pathogenesis, protection, and control. Washington, DC, ASM Press. 1994: $417-435$.

16. Turner-Warwick M. Widespread pulmonary fibrosis. In: Fishman AP (ed) Pulmonary diseases and disorders, 2nd edn, vol 1. New York, McGraw-Hill, Inc. 1988: 755-772.

17. Rees RJ, Hart PD. Analysis of the host-parasite equilibrium in chronic murine tuberculosis by total and viable bacillary counts. Br J Exp Pathol 1961; 42: 83-88.

18. McCune R, Feldmann MF, Lambert HP, McDermott W. Microbial persistence. I. The capacity of the tubercle bacilli to survive sterilization in mouse tissues. $J$ Exp Med 1966; 123: 445-468.

19. Barnes PF, Chatterjee D, Abrams JS et al. Cytokine production induced by Mycobacterium tuberculosis lipoarabinomannan. Relationship to chemical structure. J Immunol 1992; 149: 541547.

20. Friedland JS, Shattock RJ, Johnson JD, Remick DG, Holliman RE, Griffin GE. Differential cytokine gene expression and secretion after phagocytosis by a human monocytic cell line of Toxoplasma gondii compared with Mycobacterium tuberculosis. Clin Exp Immunol 1993; 91: 282-286.

21. Friedland JS, Remick DG, Shattock R, Griffin GE. Secretion of interleukin-8 following phagocytosis of Mycobacterium 
tuberculosis by human monocyte cell lines Eur $J$ Immunol 1992; 22: 1373-1378.

22. Mackaness GB, Smith N, Wells AQ. The growth of intracellular tubercle bacilli in relation to their virulence. Am Rev Tuberculosis 1954; 69: 479-494.

23. Shepard CC. A comparison of the growth of selected mycobacteria in HeLa, monkey kidney, and human amnion cells in tissue culture. $J$ Exp Med 1958; 107: 237-246.

24. Wheeler PR, Ratledge C. Metabolism of Mycobacterium tuberculosis. In: Bloom BR (ed) Tuberculosis: pathogenesis, protection, and control. Washington, DC, ASM Press. 1994: 353-385. 